\title{
Alfonso Reyes y la recepción inicial de las vanguardias en Hispanoamérica
}

\section{Alfonso Reyes and the early reception of avant-garde literature in Hispanic America}

\author{
Sebastián Pineda Buitrago \\ Universidad Iberoamericana, Puebla, México \\ sebastian.pineda@iberopuebla.mx
}

Resumen: Este artículo se propone examinar la historia de la recepción inicial de las vanguardias históricas en la literatura hispanoamericana a través de la obra de Alfonso Reyes. Sin ignorar el estallido de la Revolución Mexicana y de la Primera Guerra Mundial, el futurismo y el cubismo responden a la praxis cotidiana relacionada con el belicismo. Ambos pueden encontrarse en otros textos de Reyes escritos entre 1914 y 1924 en Madrid, donde él se había autoexiliado. Este ensayo termina comparando el vanguardismo inicial de Reyes con el de Borges y Huidobro.

Palabras claves: Alfonso Reyes, literatura, vanguardias históricas, futurismo, cubismo.

Abstract: This paper aims to examine the early reception of the historical avant-gardes in Hispanic American literature. Having in mind the outbreak of Mexican Revolution and the First World War, both futurism and cubism are in relation with a response to the daily praxis of military propaganda, and these manifestos can be found in other Reyes texts from 1913 and 1924 when he lived in auto-imposed exile in Madrid. Finally, I will discuss Reyes' early avant-garde in relation to Borges y Huidobro.

Keywords: Alfonso Reyes, Literature, Historical avant-gardes, Futurism, Cubism.

Recibido: 10 de octubre de 2018

Aceptado: 2 de febrero de 2019 http://dx.doi.org/10.15174/rv.v0i24.429 


\section{Las vanguardias o la glorificación de la violencia}

G movimiento histórico-literario conocido como "vanguardias" (en sentido de "estrategias") coincide con el estallido de la Primera Guerra Mundial y el periodo de entreguerras, porque justamente exacerbó el lenguaje o la representación de la violencia política. Las vanguardias son una exacerbación de la modernidad, es decir, del culto moderno de la violencia contra los valores burgueses que Baudelaire, en un ensayo sobre el heroísmo de 1846, definió desde dos perspectivas de clase: 1) la disidencia aristocrática, cuya figura es el dandi, y 2) la transgresión plebeya, cuya figura es el justiciero o guerrillero (Poggioli, 1964: 49). Se trata de la violencia que no se contenta con expresarse en el acto concreto, sino que exige además una exaltación teórica e ideológica, y anhela no sólo llegar a ser acción, sino hasta mito en el sentido soreliano de la palabra. Pues en 1906, en sus Réflexions sur la violence, efectivamente George Sorel argumentó que la violencia era la única forma de asegurar la escisión entre el proletariado y la burguesía (Apud. Poggioli, 1964: 51). De modo que si la Primera Guerra Mundial (1914-1918) significó el agotamiento de la Europa burguesa de la Belle Époque, cuya consecuencia inmediata fue la Revolución Rusa o Bolchevique, es de notar que este episodio está antecedido por el derrumbamiento del Estado autoritario mexicano, el de Porfirio Díaz, cuya pretensión había sido justamente imitar o representar aquella Belle Époque de manera periférica y extemporáneamente. La Revolución Mexicana no sólo reavivó el culto de la violencia o heroísmo en la transgresión plebeya -en la figura del campesino rebelde y justiciero: Venustiano Carranza, Francisco Villa y Emiliano Zapata-, sino que también provocó una disidencia aristocrática entre cierta élite intelectual que expresó a su manera un culto moderno de la violencia política. Este culto moderno, con las sutilezas propias del arte de vanguardia, se advierte en varios textos misceláneos de Alfonso Reyes (1889-1959). 
Después de la Decena Trágica (los diez días de terror que padeció la Ciudad de México entre el 9 y e 19 de febrero de 1913), en donde su padre fue asesinado, Alfonso Reyes se vio en la necesidad de vincularse al servicio exterior de la dictadura de Victoriano Huerta como una manera de echarse al exilio. El suyo no fue caso aislado. Buena parte de la élite intelectual mexicana recurrió al exilio (Cf. Krauze, 1985; Ramírez Rancaño, 2002; Garciadiego, 2010) en medio de la guerra civil. Pero cuando llegaron a Europa, como en el caso de Reyes, la propaganda bélica dominaba el escenario. Era necesaria para la movilización marcial y revolucionaria que tanto el arte como la literatura irrumpieran en los medios de comunicación masiva de entonces -las revistas, los diarios, los periódicos, el cine y la radio- difundiendo una semántica miscelánea, la cual se daba por medio de la fundición de géneros poéticos y de técnicas artísticas, transgrediendo las mediaciones institucionales. El arte de vanguardia no destruyó las instituciones (academias, universidades cenáculos, ateneos, etc.), pero desacralizó su función mediadora al poner en duda la división del trabajo. Pues la fundición entre las artes a través del periodismo (reportajes gráficos) implicó una práctica multidisciplinaria que invitaba también al escritor o al artista a discurrir sobre historia o sociología y a perfilar una opinión política como antecedente de la acción. En consecuencia, la categoría de obra de arte fue modificada totalmente por las vanguardias (Bürger, 2009: 72). En lugar de hablar de obra en cuanto género literario (poema, cuento, drama), deberíamos referirnos a la manifestación y, más específicamente, al vocabulario vanguardista presente en panfletos, epístolas, artículos de periódico o de revista, films, cartones, cuadros, collages, etc.

Si tanto el futurismo como el cubismo y el dadaísmo no tienen tanto un carácter de obra como de manifestación, no se trata de postular a Alfonso Reyes como un escritor vanguardista, sino de observar qué manifestación vanguardista arrojan algunos de sus 
textos escritos durante 1914 y 1917 independientemente del género literario (poema, cuento, drama), es decir, incluyendo también sus epistolarios y artículos periodísticos. Conviene aclarar que Reyes nunca quiso pertenecer a una escuela literaria ni abanderar ningún -ismo, de modo que las historias de la vanguardia hispanoamericana suelen pasar por alto su nombre y su obra. De ahí la insistencia en buscar una manifestación, en lugar de una obra en sí, al analizar la presencia de las vanguardias (el cubismo y el futurismo) en ciertos textos de Reyes.

La aparición del primer manifiesto futurista de Filippo Tommaso Marinetti en el periódico parisino Le Figaro, el 20 de febrero de 1909, inicia el primer ciclo vanguardista incluso para el caso de la literatura hispanoamericana (Videla de Rivero, 2011: 23). En consecuencia, resulta algo tardío la recepción de las vanguardias en México si éstas se datan a partir de la aparición del primer manifiesto estridentista del 31 de diciembre de 1921, Actual número 1, redactado y firmado por Manuel Maples Arce. Si bien el estridentismo no obtuvo el beneplácito del entonces Secretario de Cultura, José Vasconcelos, la difusión que tuvo en El Universal Ilustrado, desde el primer reportaje de Carlos Noriega Hope publicado el 24 de agosto de 1922 hasta el suplemento La novela semanal que éste introdujo en la revista a partir del 3 de noviembre 1922, aseguró su difusión y su institucionalización posterior bajo la protección estatal del gobernador de Veracruz, el general Heriberto Jara (Schneider, 1999: X). En cualquier caso, el estridentismo resulta algo tardío en relación con la aparición del primer manifiesto futurista de Marinetti. Este último fue inmediatamente comentado en la prensa mexicana de entonces. En agosto de 1909, Amado Nervo lo difundió en el artículo "Nueva escuela literaria”, que publicó en el número 4 del Boletín de Instrucción Pública. Bajo la ingenua convicción de que semejantes deseos futuristas no tendrían "futuro", Nervo tradujo y comentó los doce puntos del primer manifiesto de 
Marinetti en los que éste llamaba a glorificar la guerra, a destruir los museos y las bibliotecas y a despreciar a la mujer.

Como ven Uds., he traducido sin pestañear los doce párrafos esos, incendiarios. Y es que a mí, viejo lobo, no me asustan ya los incendios, ni los gritos, ni los denuestos, ni los canibalismos adolescentes [...] Estos niños que desprecian a la mujer, desde su futurismo ingenuo, probablemente tienen novia o amante..., que los domina por completo (Nervo, 1988: 9).

Nervo, quien vivía en calidad de diplomático en Madrid y cuya poesía siguió bajo los preceptos de la escuela modernista ya tocada de misticismo a juzgar por su poemario La amada inmóvil (1910), no advirtió que el primer manifiesto futurista preparaba la guerra. Marinetti buscó inspiración poética en la primera guerra balcánica (1912-1913) a la que asistió en calidad de corresponsal para el diario L'Intransigeant. En 1914 publicó el poemario sonoro Zang tumb tuuum: Adrianopoli ottobre 1912: parole in libertà, en el que el impacto visual de la bomba aérea que los búlgaros arrojaron desde aeroplanos para causar pánico entre los soldados turcos, según explicó posteriormente, es perceptible en el tipo de letra y en la yuxtaposición de texto-imagen (Marinetti, 2009: 177). En consecuencia, el futurismo no sólo es coetáneo del auge de la reproductividad técnica de la fotografía, el cine y el radio, sino también un correlato de las guerras mundiales del siglo xx, es decir, expresión artística o poética del industrialismo bélico. En su célebre ensayo de 1936, La obra de arte en la época de su reproductibilidad técnica, Benjamin acuñó la expresión estetización de la política para referirse a la vanguardia futurista que alimentó el fascismo de entreguerras (2003: 34). Puesto que la guerra hace posible dar una meta a los movimientos de masas sin que estos afecten las relaciones de propiedad, el futurismo exacerbó el ilusionismo burgués del l'art pour 
l'art, es decir, la autoenajenación, la aniquilación como un goce estético de primer orden. Si el fascismo hizo una estetización de la política, el comunismo respondió con la politización del arte (35). Por consiguiente, no cabe duda de que el futurismo es un correlato artístico de la carrera armamentística cuyo desarrollo ulterior, la bomba atómica sobre Hiroshima y Nagasaki, parece anunciarse en el título sonoro del poemario de Marinetti, Zang tumb tuuum, "a modo de bucle cuyo cierre posee sentido tanto ideológico como formal en su doble hongo" (Aullón de Haro, 2016: 202).

Para datar el culto de Reyes por la violencia como una manifestación vanguardista, es necesario advertir que, para él, varios postulados futuristas ya no eran -no podían ser- extraños a su cotidianidad o "praxis cotidiana". Él se había formado en un hogar regido por las costumbres militares del general Bernardo Reyes, su padre, cuyo asesinato el 9 de febrero de 1913 lo marcó para siempre. ${ }^{1}$ Las secuelas de la Decena Trágica y el exilio impuesto por Huerta a partir de agosto de 1913, bajo el disfraz de un puesto menor en la Legación Mexicana en París, lo predispusieron para asimilar ciertas expresiones vanguardistas. De ahí el distanciamiento de Reyes de la escuela modernista de Darío, Gómez Carrillo y Nervo. Pues estos escritores, si bien habían dado noticia al público hispanoamericano de los manifiestos futuristas de Marinetti, miraron dicha vanguardia con resquemor, no porque temieran quedar en la sombra, sino porque el belicismo aún no hacía parte de su "praxis cotidiana”. En cambio, a finales de 1914 cuando llegó a Madrid, el joven Alfonso Reyes ya había leído los manifiestos de Marinetti,

${ }^{1}$ Es de notar que, en vida, Reyes silenció su visión de la Decena Trágica. Solamente aludió a este episodio, al que llamó como "febrero de Caín y de Metralla", en el texto Oración del 9 de febrero, el más explícito en torno a la figura de su padre. Lo escribió en Buenos Aires en 1930 y lo mantuvo inédito durante toda su vida. En 1963 tanto su viuda Manuela Mota como su nieta Alicia Reyes lo publicaron en la editorial Era. 
cuya impresión compartió con Henríquez Ureña (2004: 201), y había visto el bombardeo de la Decena Trágica en la Ciudad de México (9-13 de febrero de 1913) y el de la fuerza aérea alemana entre el 27 de agosto y el 2 de septiembre de 1914.

En un ensayo poemático, "París cubista (Film de Avant-Guerre)", incluido en su libro de 1921, El cazador, Reyes juega con el término "film" como si se tratara de una película; juega también con el término avant-guerre (antes de la guerra), en lugar de avantgarde (vanguardia), dando a entender el sentido cómico, gracioso y juguetón del primer cubismo. En otro ensayo poemático de El cazador, titulado "Los ángeles de París", Reyes comienza por reseñar la última novela de Anatole France, La Révolte des anges, que había salido el 18 de marzo de 1914 y cuyo argumento consiste en que los ángeles descienden a París y se convierten en ciudadanos normales, para preparar una suerte de golpe de Estado que restituya a Lucifer, símbolo del conocimiento y la libertad. Pero lo que parece ser un resumen o reseńa pronto se independiza y se convierte en una recreación del tema. Los “ángeles rebeldes” son jóvenes inmigrantes rusos sin ningún futuro claro, que se mezclan con gitanas pintarrajeadas en las fondas de Montparnasse. Esos ángeles rusos, a juzgar por lo que predican (la muerte de Dios y extrańos advenimientos), viven en una suerte de comuna y entre ellos mismos practican una suerte de economía comunista: "pintan y graban, fabrican la tela de sus vestidos, hablan con suavidad, e impiden que ninguno de ellos perezca de hambre [...] hasta su retina abstracta llegan imágenes de odio y de vergüenza [tienen] la actitud del Cristo -y del Aeroplano" (Reyes, 1996a: 95). Puestos a buscar en la literatura francesa de la época, encontramos una imagen gemela en un poema de Guillaume Apollinaire titulado "Zone”, que está incluido en su poemario Alcools de 1913: “C'est le Christ qui monte au ciel mieux que les aviateurs / Il détient le record du monde pour la hauteur" (2006: 311). La torre Eiffel pastorea el rebaño 
de los puentes del Sena; los automóviles tienen un aire antiguo y la invención del aeroplano no es menos sorprendente que la ascensión de Cristo. La imagen de Cristo y del aeroplano, por otra parte, remite tanto en Apollainere como en Reyes a la deificación de la tecnología y del maquinismo. ${ }^{2}$

Si las principales características estilísticas de la prosa de vanguardia son la fragmentación, la síntesis, la depuración y la brevedad, así como el humorismo, lo metaliterario y la parodia (Millares, 2013: 35), los textos de Reyes responden a tal denominación. Pues él asimiló este tipo de manifestación vanguardista, no por el capricho de acogerse a una moda, sino por la praxis del periodismo madrileño en el que intensamente colaboró entre 1914 y 1920. Particularmente en 1915 y 1916, durante el fervor de noticias por las batallas de la Primera Guerra Mundial al otro lado de los Pirineos, Reyes escribió reseñas cinematográficas con el pseudónimo de "Fósforo" tanto en el semanario España -a veces a dos manos con Martín Luis Guzmán- como en el diario El Imparcial, fundando de algún modo la crítica de cine en lengua española (Cf. Perea, 1988; González Casanova, 2003). Las reseñas de Reyes no se quedan en un plano descriptivo o anecdótico. La influencia del cine despertó en él un interés en "pensar por imágenes", es decir, una poética o retórica visual cuya prosodia se mueve con unidades escénicas y series de cuadros o escenas (Robb, 1966: 211). Uno de sus textos más leídos, Visión de Anáhuac. 1519 (escrito en 1915 y publicado en 1917), es un ensayo poemático en el que se ha

${ }^{2}$ Apollinaire, muerto por la gripa española en 1918, llegó a pelear en el bando francés durante la Gran Guerra, donde recibió múltiples heridas por las esquirlas de una granada. El 2 de junio de 1920, Reyes ya había publicado, en el número 267 del semanario España, "La novela bodegón", una reseña sobre $L a$ Femme assise, es decir, sobre la novela inacabada de Apollinaire de reciente aparición en Francia; dicha reseña, Reyes la incluyó después en 1921 en la segunda serie de Simpatías y diferencias (Reyes, 1986: 96). 
advertido la presencia de varios planos narrativos a la manera de un collage cubista (Cf. Stanton, 2017). Este cubismo igualmente se advierte en Cartones de Madrid (1917), los ensayos o crónicas sobre la capital española que Reyes publicó a través de su amigo Julio Torri en la imprenta Cvltura de la Ciudad de México, así como en los cuentos reunidos en su libro de 1920, El plano oblicuo (Ibieta, 1981).

Ahora bien, en aras de advertir el lenguaje más bélico -vanguardista- en Reyes es necesario detenerse en la tercera parte de Calendario (1924), una serie de poemas en prosa a medio camino entre el encanto y el desencanto, entre lo heroico y lo trágico por la reciente Primera Guerra Mundial. Conviene analizar el primero de ellos, que se titula "Guynemer", en homenaje al piloto francés Georges Guynemer (1894-1917), que murió luchando contra la fuerza aérea alemana en la Primera Guerra Mundial. ¿De dónde se inspiró para escribir este texto? ¿Por qué manifestó tanto interés por la literatura bélica?

\section{Asimilación y praxis del lenguaje belicista}

En "La catharsis y el cine", una nota publicada con el seudónimo Fósforo el 11 de noviembre de 1915 en el número 2 del semanario España, Reyes no habló de ninguna película en especial, pero insistió en la mímesis cinematográfica de moverse, de marchar al frente, de luchar:

¿Qué hacer para producir la catharsis [sic], la onda de viento purificador? Echarnos a la calle cuanto antes, así fuere por la ventana como los personajes del cine; arrojarnos a un río; desbocar el auto, atropellar gentes, domar potros, ir de un hombre a otro, chocar con las cosas del mundo, desahogar, en fin, todo ese vaho y esa bruma en que naufraga la dignidad de nuestra especie. [...] 
Tienen razón los futuristas: piensan como el doctor de la Iglesia, que la suprema perfección está en ser activo; que todo es acto de la divinidad; que nos salvaremos por el movimiento, por lo cinematográfico y lo dinámico (1915:11). ${ }^{3}$

Algunas de estas ideas, casi con las mismas palabras, volvemos a leerlas en "El misticismo activo", el texto central de su libro de ensayos de 1917, El suicida. Resistirse a la guerra continental no era una muestra de pacifismo, sino otra forma de violencia si se quiere psicológica, casi morbosa, en la que se malgastaban las energías. En contra de la mentalidad burguesa, tan fatalista y desdeñosa de la vitalidad, Reyes llegó a decir: "los gases asfixiantes de las trincheras son menos dañinos que los de la chimenea doméstica” (1997: 278). Dio a entender que el pacifismo obedecía a un "morbo psicológico", a un vaho o bruma mental que impedía mirar al horizonte. A los ojos de Dios, decía, merece más el asalto del soldado que la devoción del ermitaño; quien permanece en el confort del cuarto, termina por ejercer otra manera del mal; echarse a la calle es más santo que encerrarse en casa, puesto que no hay otra manera de ser útil y activo. ${ }^{4}$ Que Espańa entrara en la Gran Guerra como el resto

${ }^{3}$ Conviene aclarar que este texto no está incluido en las obras completas de Reyes. González Casanova lo incluye en su antología (2003: 131-132). El título original, "La catharsis y el cine", se puede consultar en la Hemeroteca Digital de la Biblioteca Nacional de España.

${ }^{4}$ Probablemente, entre muchas otras fuentes, el interés que Reyes tuvo por el misticismo como una manera de propaganda bélica lo había tomado de una de las conferencias que Bergson dio en Madrid para apoyar la causa aliadófila. La traducción de una de esas charlas salió publicada en el número 69 de España, en donde leemos cómo Bergson, en efecto, aseguraba que el pueblo francés se hallaba como en un estado de misticismo, dispuesto a sacrificarse con tal de defenderse y vencer. Véase "Segunda parte de la conferencia de Henri Bergson", España, núm. 69, 18/5/1916, p. 6, el cual se encuentra disponible en Hemeroteca Digital de la Biblioteca Nacional de España. Reyes incluso le dirigió una 
de países europeos, como incluso México ya había entrado en su propia revolución, se volvió una obsesión para Reyes en simpatía con el fatalismo de la Generación del 98 y del 14. La modernidad se estaba poniendo a prueba, en buena parte, en el belicismo.

Las crónicas de batallas aéreas abundaban en la prensa española, y el nombre de Guynemer no le era desconocido a Reyes desde 1916. Probablemente se inspiró en una crónica del periodista español Manuel Aznar Zubigaray, corresponsal en Francia, publicada el 28 de agosto de 1918 en el diario El Sol y que se titula "Al volver de los frentes de batalla. Contemplando la batalla de aviones desde uno de los fuertes de Verdun”. En ella, el piloto Guynemer es recordado como una figura anińada y endeble, en contraste con la misión aérea que cumplía: derribar aviones alemanes. El periodista español, como si reportara un suceso histórico trascendental, comparaba el despegar de los aviones -en giros llenos de gracia y en juegos caprichosos- "a la emoción que causaría ver a las carabelas de los grandes navegantes españoles en el momento de abandonar el puerto y salir a la mar, empujados por el afán de descubrir nuevas tierras y añadir a la Corona de Castilla mundos desconocidos". ${ }^{5}$ La comparación, leída en nuestros días, no puede ser más desafortunada.

Reyes nunca estuvo en el campo de batalla ni fue corresponsal de guerra. Pero tuvo la suficiente imaginación o impersonalidad -la habilidad de desaparecer su "yo"- para exaltar a este joven aviador. Lo exaltó como si fuera un artista o un creador. Fiel a su pragmatismo, celebró que Guynemer hubiera conquistado el verdadero cielo, no el "cielo metafórico" de los poetas pasivos; celebró que

carta a Bergson, con fecha del 3 de mayo de 1916, hablándole de su exilio y de la Revolución Mexicana (Paulette Patout, 2099: 667).

${ }_{5}^{5}$ Manuel Aznar, "Al volver de los frentes de batalla. Contemplando la batalla de aviones desde uno de los fuertes de Verdun", El Sol, 28/08/1918. Disponible en Hemeroteca Digital de la Biblioteca Nacional de España. 
el aviador pusiera en práctica el misticismo activo y que asumiera su profesión "poseído del Dios”. Fiel a su casuística, no se detuvo en miramientos morales o éticos, pues el caso de Guynemer era el de un piloto de guerra que actuaba como tal:

Cuando comenzó a volar en la heroica escuadra de las Cigüeñas (22 muertos, 23 desaparecidos), aseguró que no se dejaría coger vivo por los contrarios. Partía en persecución del enemigo, ebrio de trepidación y retumbos, mirando estallar aquí y allá las estrellas momentáneas de la granada; se lanzaba como gavilán sobre la presa, que casi chocaba contra ella; el humo lo envolvía un instante, y las baterías lo cercaban en collares de truenos; el latido de su motor se injertaba en la palpitación de su sangre. Y súbitamente, el contrario se desgajaba entre llamas, en fantástica caída vertical de aspas y ruedas, por el camino de Luzbel. [...] ¡Oh capitán, oh héroe! De los labios de un pueblo tu nombre sube como un resuello de triunfo. Palpita tu corazón , claro astro, en el fondo de las noches de Francia (Reyes, 1995: 304 y 306).

La imagen del piloto fusionado con su aeronave ("el latido de su motor se injertaba en la palpitación de su sangre"), recuerda la estética futurista del hombre fusionado con o enamorado de la máquina. $\mathrm{Al}$ exaltar a Guynemer parece haber puesto en práctica, en especial, el manifiesto de "El hombre multiplicado y el reinado de la máquina”, que Marinetti había publicado en el segundo Manifiesto futurista, Uccidiamo il chiaro di luna (1909), proclamando el amor a la máquina por encima del anarquismo y del socialismo. Marinetti incluso llegó a decir que el maquinista, en las peores huelgas ferroviarias, nunca se atrevía a destruir su locomotora, pues ya se había encarińado con ella. El motor de una máquina equivalía a un corazón humano. En la fusión del hombre con la máquina, desde luego, Marinetti pedía superar el sentimentalismo 
tradicional por otro más dado al combate y al choque. Para él, el hombre futuro se anunciaba en el piloto de guerra:

Le type inhumain et mécanique construit pour une vitesse omniprésente sera naturellement cruel, omniscient et combatif. Il sera doté d'organes inattendus: des organes adaptés aus exigences d'un ambiance faite de chocs continus. - Nous pouvons prévoir dès ajourd'hui un développement du bréchet sur la face externe, qui sera d'autant plus considérable que l'homme future sera meilleur aviateur (Marianetti, 1973a: 112-113).

Preguntémonos por qué el "humanista" mexicano exaltó a un piloto de guerra y celebró bombardeos aéreos y hasta lanzó ovaciones patrióticas a Francia. En nuestro tiempo tal cosa nos parece cruel y ha perdido toda su novedad. Pero, si vemos bien, los hechos bélicos son juzgados por su valor atractivo o de belleza y aun por lo que guardan de especial y extraordinario. Reyes, en "Guynemer", no tiene como propósito denunciar los horrores de la realidad de la guerra, precisamente porque no busca la verdad. ¿Entonces invitaba Reyes, irresponsablemente, a negar la verdad-el horror de la guerra- bajo el culto de lo estético? Podría ser. Para James Willis Robb, el texto de "Guynemer" es un ejemplo fehaciente de la apoteosis, es decir, de la transfiguración poética, donde todas las palabras contribuyen a la metamorfosis multidimensional y a las paradojas del juego-guerra (Robb, 1975: 164:174). Por eso Reyes concibió a Guynemer como un chiquillo regocijado en derribar aviones. Incluso imaginó un diálogo entre el joven piloto y su progenitora: “'Las fuerzas tienen un límite', le había dicho su santa madre. 'Sí -contestó él-. Un límite que hay que superar. Mientras no se ha dado uno entero, no ha dado nada" (Reyes, 1995: 306). El juego de volar, para Reyes, pasaba a convertirse en un auténtico oficio y éste en una especie de misticismo activo. Como si supiera 
las confusiones que generaría su apología de un piloto de guerra, quiso justificarse:

Expliquémoslo poéticamente: lo que así excita su pulso, lo que tanta palidez comunica a su semblante de niño, es su voluntad de transfiguración, su anhelo de saltar más allá. Su mano tiembla, y parece que el héroe empieza a volar con cierto desmaño: es que ha descubierto su camino y, como todo artista en la era de la superación, olvida un poco la técnica y hace como que se equivoca a veces. Respetemos el instante sagrado (305).

La actitud ulterior del aviador francés, de olvidar un poco la técnica para abrir un nuevo camino, ya Reyes la había señalado como una manera para incentivar la voluntad de dominio y hasta de imperialismo hispano (por más políticamente incorrecto que ahora nos parezca). El 13 de junio de 1919, en El Sol, Reyes escribió el artículo "En los paraísos de la Guinea española”. En él, comenzó por lamentar que España no se acordara de que aún tenía un territorio africano entre el Cabo Formosa y el río Gabón, cerca de la costa de Camerún, casi de igual tamaño que Madrid y Barcelona juntas. Lamentó que los misioneros católicos no lograran competir con los protestantes y que, por falta de patrocinio estatal, el idioma español perdiera terreno frente al inglés. A partir del libro del historiador español J. Bravo Carbonel, Fernando Póo y el Mani, sus misterios y riquezas, su colonización (1917), Reyes reseñaba el fracaso de la colonización española en el África occidental. Sin embargo, resaltaba el papel de un agente colonial de origen vasco llamado Pedro Arriala Bengoa, quien desde 1887 se había aventurado por sí solo, por pura voluntad personal, hasta la profundidad de las selvas del río Congo en plan de cazar elefantes y enseñar el español entre los naturales. Reyes llegó al extremo de alabar al cazador Bengoa: "Sólo tú, sagrado cazador de elefantes; 
sólo tú, Bengoa, mantienes la fuerza de España. Sólo una vez recuerdan los salvajes pamúes el nombre de España, y es para vitorear a Bengoa" (1986: 42). Reyes vio en aquel agente colonial -me parece- otro epígono del misticismo activo, del hombre heroico que en circunstancias adversas se llena de voluntad personal. Frente al ecologismo y antiimperialismo de nuestros días, tal elogio no puede ser más políticamente incorrecto.

\section{Conclusiones: crítica de las vanguardias tardías}

En el primer número de la revista Síntesis, de junio de 1927, Jorge Luis Borges publicó una reseña sobre Reloj de sol, de Alfonso Reyes, que más tarde aquel incluyó como parte de El idioma de los argentinos. En ella, Borges celebró los pequeños ensayos dialogados en que el mexicano recordaba sus recientes anécdotas en Madrid. Exaltó su capacidad para hacernos simpatizar con sus amigos y hasta cierta "eficacia novelística" al definir una personalidad en cinco o seis renglones. Pero se preguntó si Reyes creía de veras en la dedicación por entero a la literatura, en la corrección durante horas de una novela, de un cuento o de un ensayo:

Este hombre tan sagaz, tan inteligente de los delicados errores y de los delicados aciertos de todo escrito, ¿creerá de veras en la venerabilidad de las letras, en la perfección durante horas? [...] Hay quien descree del arte-Quevedo, barrunto, fue uno de sus mayores incrédulos- y quien aparenta negarlo y sin embargo firma libros y corrige pruebas y reivindica para sí una prioridad, como los dadaístas (Borges, 2010: 69).

La comparación con los dadaístas no debería desatenderse, a pesar de que Borges nunca profundizó en ella ni volvió a mencionarla jamás. A su paso por Suiza en 1918, el argentino había tenido no- 
ticias del movimiento dadaísta que Tristan Tzara, George Grosz, Francis Picabia y otros poetas y artistas centroeuropeos habían iniciado en una taberna de Zúrich. Acaso leyó el Manifiesto dadá, de Tzara (seudónimo de Samuel Rosenstock), el que salió en el órgano “391” de 1918 y en el que, entre otras cosas, se decía: "Estamos hartos de las académicas cubistas y futuristas: laboratorio de ideas formales [...] Yo se lo digo: no hay comienzo y nosotros no temblamos, no somos sentimentales" (1988: 76). Los dadaístas no querían saber más de pintores, literatos, músicos, escultores, religiosos, demócratas, burgueses, revolucionarios, policías, patriotas. En fin, decían, basta de esas imbecilidades: el arte no tiene ningún valor, pues la vida es mucho más interesante. Asociar a Reyes con los dadaístas significaba sugerir, entre burlas veras, que también el mexicano estaba saturado de que unos y otros (ultraístas, creacionistas y estridentistas) escandalizaran al burgués y lucharan por el predominio de las vanguardias, cuando lo importante del arte no era amargar la existencia con vanidades vacuas, sino alegrarla.

Reyes, quien en 1927 acababa de llegar a Buenos Aires en calidad de Embajador Extraordinario y Plenipotenciario, ya parecía encontrar más emoción o tensión poética en los asuntos políticos o de Estado que en las polémicas literarias. Poco interés le suscitó el manifiesto "Ultra. Un manifiesto literario", que apareció el 15 de marzo de 1919 en el número 11 de la revista sevillana Grecia, y que se reprodujo también en la revista Cervantes en noviembre de 1919 (Sarmiento García, 2003: 14). Ni Reyes ni Gómez de la Serna firmaron ese primer manifiesto ultraísta. Lo cierto es que Reyes se carteaba con Vicente Huidobro desde 1914 y sabía que a finales de 1916 éste se había establecido en París, donde fundó con Pierre Reverdy la revista Nord-Sud, pero nunca tuvo mucho contacto con el poeta chileno cuando éste abandonó la capital francesa para radicar por un tiempo en Madrid. Desde el 30 de agosto de 1916, en la primera carta que Reyes le respondió a Huidobro, le reco- 
mendó al poeta leer a Ortega y conocerlo si el ensayista español -de visita en Argentina- se pasaba por Chile, donde para entonces Huidobro residía: "Está en la Argentina. Si llega a ir a por su país, procure conocerlo. Hombre de mucho talento, y muy vigoroso, a quien, en mi concepto, le estorba la actitud académica que la vida le ha obligado a adoptar" (Reyes, 1995: 33). Ni en Argentina ni en Chile vio Huidobro a Ortega. Pero, por recomendación de Reyes, Huidobro sí leyó uno de sus libros de aquellos años, El Espectador I, y a la luz de los conceptos estéticos de Ortega -con los que Reyes simpatizaba-, Huidobro deslindó el creacionismo de la pura fantasía. En su carta abierta a Paul Dermée con el título de "La littérature de langue espagnole d'aujourd'hui", que salió publicada en la revista parisina L'Esprit Nouveau en noviembre de 1920, Huidobro desestimó el movimiento ultraista a partir de la lectura de Ortega: "Le philosophe espagnol Ortega y Gasset, dans son livre El Espectador, en 1916, attaque cet emploi du mot «créer» comme impropre, car, dans l'art comme dans la science, rien ne se crée mais s'invente" (Huidobro, 2003: 1299-1300).

Hacia mediados de 1918, efectivamente, "Huidobro llegó a la capital espańola con las novedades cubo-futuristas de Apollinaire, Blaise Cendrars, Jean Cocteau y otros" (Schwartz, 2006: 96). Pero Reyes, a diferencia de casi todos los poetas españoles jóvenes, no quedó asombrado. Ningún comentario le despertaron los dos poemarios que Huidobro publicó en 1918, Ecuatorial y Poemas árticos. En lugar de proponer otro -ismo o de participar en esas polémicas que consideraba tardías y absurdas, en 1921 planeó, con Juan Ramón Jiménez, la edición de la revista Índice. La editorial del primer número se opuso a cualquier colectivismo: "Índice no es una revista de grupo" (1921: 1). La sentencia no podía ser más diciente. En ese primer número, Reyes se las ingenió para publicar un epistolario apócrifo entre Góngora y el Greco (pseudónimo de Doménikos Theotokópoulos). Se titula así: "Góngora y el Greco: precursores 
del cubismo. Un epistolario inédito" (Reyes, 1955: 254-255). ${ }^{6}$ En la introducción a este falso epistolario, además de lanzar una ironía contra L'Esprit Nouveau -la revista parisina volcada a la publicidad de los escritores más vanguardistas-, Reyes denunció irónicamente la arrogancia de creacionistas y ultraístas. Sólo que ninguno de ellos siguió su juego: jamás se lo tomaron a mal o tal vez ni siquiera se dieron por enterados. Tanta discreción o fineza, ¿no ha perjudicado la valoración de la obra literaria de Reyes desde un punto de vista más vanguardista?

Por otra parte, Reyes compartió la dimensión filosófica que Ortega elaboró más tarde en La deshumanización del arte, un ensayo que éste publicó en forma de artículos entre enero y febrero de 1924 en el diario El Sol y que en 1925 reunió en libro. La principal doctrina de Ortega es que el placer estético, para el artista nuevo, emana del triunfo sobre lo humano: "el placer estético tiene que ser un placer inteligente” (Ortega, 1983: 369). Tal noción guarda estrecha correspondencia con lo que Reyes pedía en el arte nuevo: despojarse de sentimentalismos inútiles. Sin embargo, las ideas de Reyes no hicieran tanta carrera como las de Ortega. La deshumanización del arte llegó a tomarse como una teoría de las vanguardias hispánicas y a veces hasta como un documento programático, sin ser tampoco Ortega un apologista del arte de vanguardia. Él también mostró escepticismo al respecto y su terminología de entonces se movía en un terreno incierto. En cualquier caso, si el artista de las vanguardias de entreguerras se juzgó como alguien deshumanizado, el artista de la Posguerra, se juzgó como alguien humanista en tanto pacifista. De modo que Reyes, "el gran humanista mexicano", evadió quizás con cierto pesar identificarse con los aportes

${ }^{6}$ Puede consultarse también como Anónimo, "La Rosa de Papel”, suplemento de la revista Índice, núm. 1, Madrid, 1921, p. 21. Disponible en Hemeroteca Digital de la Biblioteca Nacional de España 
y discusiones de las vanguardias históricas por cuanto estas terminaron asociadas en buena parte con los fascismos y totalitarismos.

En la actualidad, a pesar de innumerables intentos neovanguardistas -happenings, performances, escritura automática, etc.- ya no es posible alcanzar el sentido primigenio de las vanguardias históricas. Pues, por un lado, la categoría de obra o de autor ha sido institucionalizada por las redes sociales, el mass media, las editoriales comerciales, los premios estatales, los cargos políticos o académicos, siendo improbable irrumpir en la esfera pública sin dichos intermediarios o instituciones. Por otro lado, la taxonomía del espacio académico tiende a limitar el impacto de los estudios sobre el arte y la literatura a cierto hermetismo, es decir, a una interpretación sin contextualización ni interdisciplinariedad suficiente; o bien, a dar primacía al contenido sociológico en detrimento de la forma poética o estética. En consecuencia, y sin perder de vista que las vanguardistas históricas son correlatos de las guerras mundiales, el fenómeno vanguardista se manifestó en un periodo de rupturas y crisis institucionales cuya secuela aún nos afecta.

\section{Bibliografía}

Apollinaire, Guillaume, 2006, Obras esenciales I, edición bilingüe, Rubén Silva Pretel (trad.), Pontificia Universidad Católica del Perú, Lima.

Aullón de Haro, Pedro, 2016, Idea de la literatura y teoría de los géneros literarios, Universidad de Salamanca, Salamanca.

Benjamín, W., 2003, La obra de arte en la época de su reproductibilidad técnica, Andrés E.Weikert (trad.), Ítaca, México.

Borges, "Alfonso Reyes, Reloj de sol”, en Discreta efusión. Jorge Luis Borges y Alfonso Reyes. Epistolario (1923-1959) y crónica de una 
amistad, Carlos García (ed.), Bonilla Artigas/El Colegio de México, México, 2010, pp. 67-69.

Bürger, Peter, 2009, Teoría de la vanguardia, Tomás Bartoletti (trad.), Kas Cuarenta, Buenos Aires.

Colombi, Beatriz, 2004, Viaje intelectual. Migraciones y desplazamientos en América Latina (1880-1915), Beatriz Viterbo, Rosario.

Díaz Sánchez, Julián, 1998, La “oficialización” de la vanguardia artística en la postguerra. (El informalismo en la critica de arte y los grandes relatos), tesis doctoral, Ediciones de la Universidad de Castilla-La Mancha, Cuenca.

García García, Isabel, 2004, Orígenes de las vanguardias artísticas en Madrid (1909-1922), Fundación Provincial de Artes Plásticas Rafael Botí, Córdoba.

García, Carlos (ed.), 2005, Alfonso Reyes / Vicente Huidobro, Correspondencia, El Colegio Nacional, México.

, (ed.), 2010, Discreta efusión. Jorge Luis Borges y Alfonso Reyes. Epistolario (1923-1919) y crónica de una amistad, El Colegio de México/Bonilla Artigas Ediciones, México.

Garciadiego, Javier, 2010, "Los exiliados por la Revolución mexicana”, en Revolución y exilio en la historia de México: del amor de un historiador a su patria adoptiva: homenaje a Friedrich Katz, Javier Garciadiego y Emilio Kouri (eds.), El Colegio de México/ Era/The University of Chicago, Centro Katz de Estudios Mexicanos, México, pp. 539-565.

González Casanova, Manuel, 2003, El cine que vio Fósforo: Alfonso Reyes y Martín Luis Guzmán, FCE, México.

Gutiérrez Girardot, Rafael, 2004, Entre la Ilustración y el expresionismo. Figuras de la literatura alemana, FCE, Bogotá.

Himelblau, J., 1968, "La metáfora en la prosa de Alfonso Reyes", Hispanic Review, vol. 36, núm. 1, enero, pp. 44-53. 
Huidobro, Vicente, 2003, "La littérature de la langue espagnole d'aujourd'hui. Lettre ouverte à Paul Dermée", en Obra poética, Cedomil Goic (ed.), Archivos/Allca Xx/Université Paris X, Madrid, pp. 1299-1300.

Ibieta, Gabriela, 1981, "Alfonso Reyes como precursor de las vanguardias en Hispanoamérica”, Chasqui; Revista de Literatura Latinoamericana, vol. 10, núm. 2/3, febrero-mayo, pp. 47-53.

Krauze, Enrique, 1985, Caudillos culturales de la Revolución mexicana, SEP/Siglo XxI, México.

Martínez, José Luis (ed.), 2004, Alfonso Reyes / Pedro Henríquez Ureña, Correspondencia I. 1907-1914, FCE, México.

Marinetti, Filippo Tommaso, 1973, “À bas le Tango et Parsifal!”, en Futurisme. Manifestes. Documents. Proclamations, Giovanni Lista (ed), L'Age D’Homme, Lausana, pp. 351-353.

, 1973a, "L'Homme multiplié et le règne de la Machine", en Giovanni Lista, Futurisme. Manifestes. Documents. Proclamations, L'Age D'Homme, Lausana, pp. 112-113.

, 2009, "Geometrical and mechanical splendor and the numerical sensibility" [18 de marzo de 1914], Futurism. An Anthology, Lawrence Rainey, Christine Poggi y Laura Wittman (eds.), Yale University Press, New Haven/Londres.

Millares, Selena, 2013, "Introducción”, Prosas hispánicas de vanguardia. Antología, Cátedra, Madrid.

Nervo, Amado, 1988, "Nueva escuela literaria” [1909], en Manifiestos, proclamas y polémicas de la vanguardia literaria hispanoamericana, Nelson Osorio (ed.), Biblioteca Ayacucho, Caracas, pp. 8-10.

Ortega y Gasset, José, 1983, La deshumanización del arte, en Obras completas III, Revista de Occidente, Madrid. 
Patout, Paulette, 2009, Alfonso Reyes y Francia, Isabel Vericat (trad.), El Colegio de México/Gobierno del Estado de Nuevo León, México.

Perea, Héctor, 1988, La caricia de las formas: Alfonso Reyes y el cine, UAM, México.

Pineda Buitrago, Sebastián, 2015, El exilio creador: la obra literaria de Alfonso Reyes en Madrid (1914-1924), tesis doctoral, El Colegio de México, México.

, 2015a, "Pensar con imágenes: análisis de 'Huelga (ensayo en miniatura)', de Alfonso Reyes”, en Portal de la Capilla Alfonsina de la Universidad Autónoma de Nuevo León (16 de julio). Disponible en: http://capillaalfonsina.uanl.mx/pensarcon-imagenes-analisis-de-huelga-ensayo-en-miniatura-de-alfonso-reyes/ (Consultado: 8/X/2018).

Poggioli, Renato, 1964, Teoría del arte de vanguardia, Rosa Chacel (trad.), Revista de Occidente, Madrid.

Ramírez Rancaño, 2002, La reacción mexicana y su exilio durante la Revolución de 1910, UnAM, México.

Reyes, Alfonso, 1955, Cartones de Madrid [1917], en Obras completas II, FCE, México.

, 1955, "Huelga (ensayo en miniatura)" [1917], publicado en Las vísperas de España [1937], en Obras completas II, FCE, México.

, 1989, Burlas literarias: 1919-1922, en Obras Completas XXIII, fCE, México.

, 1986, Simpatias y diferencias. Segunda serie [1921], en Obras completas IV, FCE, México.

,1990, Oración del 9 de febrero [póstumo, 1963], en Obras completas XXIV, FCE, México.

, 1995, "Guynemer", en Obras Completas II, FCE, México. 
, 1996, El suicida. Libro de ensayos [1917], en Obras completas III, FCE, México.

,1996, El cazador. Ensayos y divagaciones [1921], en Obras completas III, FCE, México.

Robb, James Willis, 1975, El estilo de Alfonso Reyes. Imagen y estructura, FCE, México.

Robles, Martha, 1993, Espiral de voces, unam, México.

Sarmiento García, José Antonio, 2013, Las veladas ultraístas, Editorial de la Universidad de Castilla la Mancha, Cuenca.

Schneider, Luis Mario, 1999, El estridentismo 1922-1927, UNAM, México.

Schwartz, Jorge, 2006, Las vanguardias latinoamericanas. Textos programáticos y críticos, FCE, México.

Stanton, Anthony, "Identidad nacional y construcción textual en Visión de Anáhuac (1519)", en El ensayo en diálogo II, Liliana Weinberg (ed.), unam, México, pp. 319-348.

Tristan Tzara, 1988, “Manifiesto Dadá (1918)”, Luis RodríguezEmbil (trad.), en Manifiestos, proclamas y polémicas de la vanguardia literaria hispanoamericana, Nelson Osorio (ed.), Biblioteca Ayacucho, Caracas.

Urrutia, Jorge, 2000, "Cine y poesía”, Príncipe de Viana. Anejo, núm. 18, pp. 405-432.

Videla de Rivero, 2011, Direcciones del vanguardismo hispanoamericano. Estudios sobre poesía de vanguardia: 1920-1930. Documentos, Editorial de la Universidad del Cuyo/Ediunc, Mendoza. 